\title{
Path analysis on effects of main economic traits on the yield of YU6, a japonica $x$ indica hybrid rice line
}

\author{
Liu Weiming \\ Taizhou Vocational College of Science \& Technology, Zhejiang, Taizhou \\ 318020, China \\ 15157622288@139.com
}

\begin{abstract}
To further explore the effect of major factors on the yield of a line of japonica $\mathrm{x}$ indica hybrid rice, to clarify technical approaches to high efficient high yield production, the author analyzed 237 groups of data from 9 years in 6 counties of Taizhou. With correlation, regression, and path analyses, effects of major economic traits on the yield were determined. An effective approach to high efficient high yield production is to increase a seed setting rate and to produce large panicles while ensuring the number of productive panicles.
\end{abstract}

Keywords: japonica $\mathrm{x}$ indica hybrid rice, economic trait, yield, path analysis, technical approach

\section{Introduction}

Hybridization of japonica rice with indica rice can potentially produce superior hybrids. YU6 is a hybrid that was created by mating between Yg2a and K6001. This line has been evaluated by Zhejiang Science and Technology Department in June 2005. YU6 is the first japonica $x$ indica hybrid rice variety that passed the provincial evaluation (Zhe Ke Jian Zi [2005]\#235). It has also passed the examination of experts organized by the Department of Agriculture of China in August, 2006, which confirmed that YU6 is the first recommended japonica $\mathrm{x}$ indica hybrid line (Nong Ke Ban [2006] \#36). YU6 participated in the single cropping rice regional test of Zhejiang Province in 2002 and 2003. Its average yield was $563.3 \mathrm{~kg} / \mathrm{mu}$, which was $11.4 \%$ greater than that of the control, Xiushui 63. It takes 156.4 days to mature, which is 4.7 days longer than that of the control. YU6 has 13.4 thousand productive panicles per $667 \mathrm{~m} 2$ and 210.1 spikes per panicle on average. Its seed setting rate is $72.9 \%$ and the 1000 -seed weight is $24.7 \mathrm{~g}$. It is medium in resistance to rice blast disease and bacterial leaf blight, but susceptible to brown planthopper. Its grain 
quality is very good, with a head rice rate $66.9 \%$, kernel chalkiness rate $16.4 \%$, chalky $1.9 \%$, and transparent 2.5 , gel consistency $69.5 \mathrm{~mm}$, the length to width ratio 2.3 , and amylose $14.0 \%$. YU6 inherited both the loose aromatic quality of indica rice and the elastic, sweet and glutinous character of japonica rice. YU6 has high hills, strong stems, straight leaves, large panicles, well developed primary branches, thick leaf sheath and excellent maturity looking. It is resistant to cold and lodging.

In recent years, along with the successful creation and application of YU6 hybrid rice, studies on the cultivation of this type of rice started to erupt [1-9]. In order to explore the effect of its main economic traits on the yield, clarify the technical approach for high efficiency, high yield production, the author has analyzed data from the past on economic trait and yield, conducted regression, and path analysis before [10]. Now, the author has collected more data from additional years and sites, conducted further analysis on the influences of major economic traits on the yield of japonica $\mathrm{x}$ indica hybrids, using YU6 as a representative.

\section{Materials and Methods}

\subsection{Data for panicle, grain weights}

Table 1 shows the data for panicles and grains of YU6 cultivated in 6 counties, districts or cities.

Table 1. Panicle and grain characteristics of YU6 based on the yield category

\begin{tabular}{|c|c|c|c|c|c|c|c|}
\hline $\begin{array}{c}\text { Yield } \\
\text { level } \\
/\left(\mathrm{kg} / \mathrm{hm}^{2}\right)\end{array}$ & Paddy & $\begin{array}{c}\text { Average } \\
\text { productive } \\
\text { panicles } \\
/\left(\mathrm{million}^{2} /\right. \\
\left.\mathrm{hm}^{2}\right)\end{array}$ & $\begin{array}{c}\text { Average } \\
\text { grains } \\
\text { /panicle }\end{array}$ & $\begin{array}{l}\text { Average } \\
\text { filled } \\
\text { grains } \\
\text { /panicle }\end{array}$ & $\begin{array}{c}\text { Averag } \\
\text { e seed } \\
\text { setting } \\
1 \%\end{array}$ & $\begin{array}{c}1000- \\
\text { seed } \\
\text { weigh } \\
\text { t/g }\end{array}$ & $\begin{array}{c}\text { Average } \\
\text { yield } \\
/(\mathrm{kg} / \\
\left.\mathrm{hm}^{2}\right)\end{array}$ \\
\hline$>11250$ & 16 & 1.7795 & 322.48 & 290.98 & 89.75 & 23.28 & 11616.13 \\
\hline $\begin{array}{l}\leq 11250- \\
>10500\end{array}$ & 28 & 1.7758 & 310.28 & 275.75 & 88.75 & 23.50 & 10782.43 \\
\hline $\begin{array}{l}\leq 10500 \\
>9750\end{array}$ & 55 & 1.6255 & 321.31 & 284.67 & 88.36 & 23.66 & 10064.32 \\
\hline $\begin{array}{c}\leq 9750 \\
>9000\end{array}$ & 48 & 1.5552 & 324.97 & 285.31 & 86.70 & 23.70 & 9385.09 \\
\hline $\begin{array}{l}\leq 9000 \\
>8250\end{array}$ & 50 & 1.6347 & 304.51 & 251.45 & 82.52 & 23.71 & 8657.76 \\
\hline $\begin{array}{c}\leq 8250 \\
>7500\end{array}$ & 30 & 1.5678 & 299.65 & 238.75 & 79.58 & 23.60 & 7958.60 \\
\hline $\begin{array}{c}\leq 7500- \\
>6495\end{array}$ & 10 & 1.6979 & 288.30 & 219.21 & 76.64 & 23.20 & 7093.35 \\
\hline
\end{tabular}




\subsection{Analysis Method}

Using YU6 as a representative, the author performed correlation and regression analyses, and finally, path analysis to determine the relationship between each of the major economic traits and yield, the relationship among these traits in the japonica $x$ indica rice line, to clarify the approaches for high yield and high efficiency.

\section{Results and Analysis}

\subsection{Correlation analysis}

As shown in Table 2, among the 5 traits, 4 traits showed a very significant positive correlation with the yield, except that the 1000-seed weight displayed a slight negative correlation. Further analysis on relationships among the five traits indicates that there were very significant negative relationship between the number of productive panicles and the number of gains per panicle as well as the number of filled grains per panicle. There was a significant negative relationship between the number of productive panicles and the seed setting rate. The number of grains per panicle was negatively correlated with the number of filled grains per panicle. The number of filled grains per panicle was very significantly correlated with the seed setting rate. The 1000-seed weight was weakly negatively correlated with the other four traits. Thus, among the five main economic traits, although there were very significant correlations among four traits, the 1000-seed weight was weakly correlated with the yield. The relationships among the five traits were also complex. To explore and formulate a standard for high efficient cultivation of the hybrid rice, it is therefore important to pay attention to the compatibility among these economic traits, so that the positive contribution of each trait can be maximized.

Table 2. Correlation coefficients among traits

\begin{tabular}{cccccc}
\hline & $\begin{array}{c}\text { grains per } \\
\text { panicle }\end{array}$ & $\begin{array}{c}\text { filled grains } \\
\text { per panicle }\end{array}$ & $\begin{array}{c}\text { seed setting } \\
\text { rate }\end{array}$ & $\begin{array}{c}1000 \text {-seed } \\
\text { weight }\end{array}$ & actual yield \\
\hline $\begin{array}{c}\text { productive } \\
\text { panicles }\end{array}$ & $-0.6852^{* *}$ & $-0.6268^{* *}$ & $-0.1355^{*}$ & -0.1254 & $0.1948^{* *}$ \\
grains per \\
panicle
\end{tabular}

Note: $* \mathrm{P}<0.05, * * \mathrm{P}<0.01$ 


\subsection{Stepwise regression analysis}

A regression equation was obtained from a stepwise regression analysis on 237 groups of data, based on the principle of maximizing the correlation coefficient: $\hat{y}=-13011.07+44.65 x_{1}+7.70 x_{2}+18.37 x_{3}+35.47 x_{4}+201.54 x_{5} \pm 721.04$

where, $x_{1}$ is the number of productive panicles, $x_{2}$ the number of grains per panicle, $x_{3}$ the number of filled grains, $x_{4}$ seed setting rate, $x_{5}$ the 1000-seed weight. Their ranges were, respectively, 1108.5 2161.5 thousand $/ \mathrm{hm}^{2}, 214.10 \sim 453.18$ grains/panicle, 168.70 407.00 grains/panicle, $65.82 \% \sim 96.60 \%$ and $21.42 \sim 25.2 \mathrm{~g}$. The range of $y$ (yield) was $6495.00 \sim 12540.00 \mathrm{~kg} / \mathrm{hm}^{2}$ 。

The $\mathrm{F}$ value of the above equation was 73.52 , which is very significant. An analysis of the partial regression coefficients indicates that the number of productive panicles per $\mathrm{hm}$ had the greatest effect $\left(r\left(y, x_{1}\right)=0.6768\right)$, followed by sequentially the number of grains per panicle $\left(r\left(y, x_{2}\right)=0.0937\right)$, the number of filled grains per panicle $\left(r\left(y, x_{3}\right)=0.1871\right)$ and the seed setting rate $\left(r\left(y, x_{4}\right)=\right.$ $0.1101)$. However, these traits were interdependent to a certain extent. Because multivariate regression analysis has multiple co-linearity, it is not easy to judge contribution of each trait. The path analysis has effectively determined the direct effect of each variable on the result, allowed estimating the indirect effect of an independent variable, thus enabled the direct comparison of the importance of each trait on the yield $[8,9,10]$. Therefore, the author also performed a path analysis to determine effects of the major economic traits on yield in japonica $\mathrm{x}$ indica rice.

\subsection{Path analysis}

A path analysis on five major economic traits selected from the stepwise regression analysis was conducted. Results indicates that the number of productive panicles had the greatest contribution, followed by the number of filled grains per panicle, the number of grains per panicle, the seed setting rate and the 1000 -seed weight (Table 3).

Table 3. Path analysis

\begin{tabular}{ccccccc}
\hline Factor & $\begin{array}{c}\text { Direct } \\
\text { effect }\end{array}$ & via $\mathrm{x}_{1}$ & via $_{2}$ & via $\mathrm{x}_{3}$ & via $_{4}$ & via $_{5}$ \\
\hline$x_{1}$ & 0.8171 & & -0.1734 & -0.4041 & -0.0292 & -0.0155 \\
$x_{2}$ & 0.2531 & -0.5598 & & 0.5252 & 0.0134 & -0.0023 \\
$x_{3}$ & 0.6447 & -0.5122 & 0.2062 & & 0.1291 & -0.0094 \\
$x_{4}$ & 0.2157 & -0.1107 & 0.0157 & 0.3859 & & -0.0093 \\
$x_{5}$ & 0.1240 & -0.1024 & -0.0046 & -0.0490 & -0.0161 & \\
\hline
\end{tabular}


The number of productive panicles had the greatest direct effect, with a direct path coefficient 0.8171 . But it had negative effects through the other four traits, especially through the number of filled grains per panicle, with the path coefficient -0.4041 . Thus, an increase in the number of productive panicles affected not only the number of grains per year, seed setting rate and the 1000-seed weight, but largely the number of filled grains. The overall effect of the number of productive panicles on the yield was $r=0.1948$.

The number of grains per panicle had little effect on the yield, with a direct path coefficient 0.2531 . It had a large indirect effect through the number of productive panicles negatively and through the number of filled grains per panicle positively, with coefficients -0.5598 and 0.5252 . Its positive indirect effect through seed setting rate and negative indirect effect through the weight of ones thousand grains were small, being 0.0134 and -0.0023 . The overall effect on yield from the number of grains per panicle was $r=0.2295$.

The number of filled grains had a large direct effect on the yield, with a direct path coefficient 0.6447 . Its negative indirect effect was large through the number of productive panicles, with a coefficient -0.5122 . Its indirect positive effects through the number of grains per panicle and through the seed setting rate were smaller, with coefficients 0.2062 and 0.1291 . Its negative effect through the 1000-seed weight was weak. The number of filled grains per panicle had not only a large direct effect, but also a large overall effect on the yield, being 0.4584 . Therefore, while considering other traits especially the number of productive panicles, attention should be paid to increase the number of grains per panicle, especially the number of filled grains per panicle.

The seed setting rate had a direct path coefficient 0.2157 , a large positive indirect effect coefficient 0.3859 through the number of filled grains per panicle. Its negative indirect effects through the number productive panicles and the 1000-seed weight, positive indirect effect through the number of grains per panicle were small. The overall effect of the seed setting rate on the yield was 0.4973 .

The 1000-seed weight had the smallest direct effect on the yield, with a direct path coefficient 0.1240 . It had not only small negative values for indirect effects through other traits, but also a negative overall effect on the yield. Thus, it is not advisable to increase the 1000-seed weight towards the goal of high efficient production.

\section{Discussion and Conclusion}

Economic traits affect not only directly the yield, but also indirectly through their influence on other traits. Through the above analysis on YU6, a representative 
of japonica $\mathrm{x}$ indica hybrid rice lines, it can be seen that the technical road to high efficient high yield production is to increase seed setting rate and produce large panicles while ensuring the number of productive panicles.

The stepwise regression analysis retained 5 factors that affect the yield. Path analysis results indicate that the number of productive panicles has the greatest influence on the yield, followed by the number of filled grains per panicle, the number of grains per panicle, seed setting rate and the 1000-seed weight. The previous stepwise regression analysis [7] removed the number of grains per panicle due to its insignificant effect. It indicates that the number of filled grains per panicle contributed the greatest influence, followed by the number of productive panicles, the 1000 -seed weight and the seed setting rate. Although the first two most import factors are the same between the current analysis and the previous analysis, the order of these two factors has changed. This is due to the retention of the number of grains per panicle in the stepwise analysis in the current analysis. It is clear that the number of filled grains per panicle is highly dependent on the number of grains per panicle, and they were collinear. The current identified technical approach to high efficient, high yield production is the same as previously reported. The current study is more reliable since it had more data and these data covered a longer period.

\section{Literature cited}

[1] Zhang Zujian,Yang Jianchang,Zhou Chunhe.Characteristics of matter production of intersubspecific hybrid rice combinations. JIANGSU AGRICULTURAL

RESEARCH, 1999,20(1):1-8

[2] Ye Shuguang.Performance of New Japonica Hybrid Rice Combination Yongyou 6 and Its High-yielding Cultural Techniques at Wenzhou, Zhejiang.HYBRID RICE, 2006,21(3):58-59

[3] Zheng Jia-cheng.Main characters and cultural techniques of the new hybrid rice combination "Yongyou No.6".2006(4):409-410

[4] Li Guo-feng, Song Ping, Cao Xian-zu. Studies on the relationship between grain sink activity of Japonica/Indica hybrid rice and its grain filling. ACTA BOTANICA BOREALI-OCCIDENTALIA SINICA. 2000,20(2):179-186

[5] Shen Bo Wang Xi.Changes of Root Exudate of Indica-Japonica Hybrid Rice and Its Relation to Leaf Physiological Traits. CHINESE JOURNAL OF RICE SCIENCE, 2000,14(2):122-124

[6] Liu Wei-ming,Zhao Yi-fu,Yan Bo-lin.Study on Transplanting Technology and $\mathrm{N}$-application Technology of Yongyou 6 as Single Cropping Late Hybrid 
Rice.SEED, 2007,26(12):112-114

[7] GONG Li-ying, DU Xing-bin, LIU Guo-lan . Research on seed production of water-saving and drought-resistant japonica hybrid rice Hanyou 8 ' by machine ' transplanting. Acta Agriculturae Shanghai,29(4):18-22

[8] Bai Pu.High-efficient Ecological Cultivation Techniques of New Indica-japonica Hybrid Rice Yongyou 9. Hybrid Rice,2012,27(2):41-43

[9] Liu Wei-ming. tudy on the High Yield and High Efficiency Cultivation Technique of Indica-japonica Intersubspecific Hybrid Rice as Single-cropping Late Rice. Hubei Agricultural Sciences,2011,50(18):3684-3686

[10] Liu Weiming.Correlation, Multiple Regression and Path Analysis between Yield Traits and Yield on Intersubspecific Hybrid Rice. Chinese Agricultural Science Bulletin, 2009,25(1):232-235 